\title{
Physico-chemical characterisation of three-component co-amorphous systems generated by a melt-quench method
}

\author{
A. D'Angelo ${ }^{1}$ B. Edgar ${ }^{1}$ A. P. Hurt ${ }^{1}$ M. D. Antonijević ${ }^{1}$ (D)
}

Received: 28 December 2017 / Accepted: 7 April 2018/Published online: 23 April 2018

(C) The Author(s) 2018

\begin{abstract}
The purpose of this work was to evaluate the possibility of creating a ternary co-amorphous system and to determine how the properties of a co-amorphous material are altered by the addition of a selected third component. Piroxicam and indomethacin form a stable co-amorphous with the $T_{\mathrm{g}}$ above room temperature. The third component added was selected based on tendency to crystallise (benzamide, caffeine) or form amorphous (acetaminophen, clotrimazole) on cooling. Generated co-amorphous systems were characterised with TGA, HSM, DSC, FTIR and XRD. Stable ternary co-amorphous systems were successfully generated, which were confirmed using XRD, DSC and FTIR analysis. In all cases, $T_{\mathrm{g}}$ of the ternary system was lower than the $T_{\mathrm{g}}$ of the binary system, although higher than that of the individual third component. Upon storage for 4 weeks, all created ternary systems showed significantly smaller variation in $T_{\mathrm{g}}$ compared to the binary system. Stable three-component co-amorphous systems can be generated via melt-quench method using either a crystalline or an amorphous third component. Addition of third component can alter the $T_{\mathrm{g}}$ of co-amorphous system and in all cases created more stable co-amorphous system upon storage. Physical parameters may not be sufficient in predicting the resulting $T_{\mathrm{g}}$; therefore, knowledge of chemical interaction must be brought into equation as well.
\end{abstract}

Keywords Co-amorphous $\cdot$ Stability $\cdot T_{\mathrm{g}} \cdot$ Crystallinity $\cdot$ Amorphicity

\begin{tabular}{ll}
\multicolumn{2}{l}{ Abbreviations } \\
AC & Acetaminophen \\
API & Active pharmaceutical ingredient \\
ATR-FTIR & Attenuated total reflectance-Fourier \\
& transform infrared spectroscopy \\
BZD & Benzamide \\
CAF & Caffeine \\
CTMZ & Clotrimazole \\
DSC & Differential scanning calorimetry \\
HSM & Hot-stage microscopy \\
IND & Indomethacin \\
NCE & New chemical entity \\
PXC & Piroxicam \\
$T_{\mathrm{c}}$ & Crystallisation temperature \\
$T_{\mathrm{g}}$ & Glass-transition temperature \\
TGA & Thermogravimetric analysis \\
$T_{\mathrm{m}}$ & Melting temperature \\
XRD & X-ray diffraction
\end{tabular}

M. D. Antonijević

M.Antonijevic@greenwich.ac.uk

1 Faculty of Engineering and Science, University of Greenwich, Chatham Maritime, Kent ME4 4TB, UK

\section{Introduction}

Approximately $90 \%$ of new chemical entities (NCE) and $40 \%$ of drugs on the market are poorly water soluble [1,2]. Low-solubility drugs are characterised by slow dissolution rates and slow drug adsorption which lead to inadequate bioavailability and gastrointestinal toxicity [3]. Therefore, solubility improvement is a critical challenge in drug development.

Alteration of the solid state of a drug from crystalline to amorphous form offers improved apparent solubility and dissolution that lead to an increase in bioavailability [4]. Amorphous materials are characterised by short-range structural order, lacking the long-range order that instead is typical of crystalline solids. They retain an excess of enthalpy, entropy and Gibbs free energy, which is responsible for the improved apparent solubility and dissolution rate. As energy is released from the system, amorphous materials convert into their crystalline counterpart, by doing so the properties of the materials inevitably change [5-7]. 
Amorphous materials are often produced by a quenchcooling method where samples are melted and rapidly cooled so that molecular conformation of the liquid material is preserved into the solid. Amorphous materials can also be generated by introduction of energy in the system by energetic grinding or by fast solvent removal. Different preparation methods may induce different molecular organisations. Therefore, properties of the generated amorphous material might vary [8].

As the kinetic interactions between the polymer and the amorphous active ingredient improve dissolution rate, bioperformance and stability, amorphous active ingredients are preferably delivered as polymeric solid dispersions. [9]. However, miscibility of the active ingredient in the polymer is one of the major issues in amorphous solid dispersions [10-12]. To overcome poor miscibility issues, the amount of polymer is increased, and this causes volume enlargement of the dosage form [13, 14]. Furthermore, amorphous materials are more hygroscopic than crystalline materials and the glass-transition temperature of most amorphous drugs is lowered, even with only very small water content [15-18]. Therefore, the phase change of an amorphous active ingredient dispersed in a polymer is facilitated by the hygroscopic nature of the polymer adopted, which has caused the recall of many products by the FDA [1].

An amorphous dispersion of low molecular weight ingredients is defined as a co-amorphous mixture [19]. Coamorphous drug delivery systems have recently attracted the interest in the pharmaceutical field to overcome limitations of solid dispersions and improve bioavailability and stability of the single amorphous components [20].

A co-amorphous is frequently composed of two low molecular weight co-formers and primarily identified by a single glass-transition temperature $\left(T_{\mathrm{g}}\right)$, indicating that the components are miscible and are interacting. Low molecular weight co-formers such as amino acids and saccharides have shown to stabilise amorphous poorly soluble drugs by generation of co-amorphous systems [21, 22]. Active ingredients are also used as low molecular weight co-formers with the advantage of the co-administration of therapeutics. The first example presented in the literature was proposed by Yamamura et al. [23] where a stable coamorphous of cimetidine and indomethacin was generated by solvent evaporation method. Since then, multiple coamorphous systems composed of two active ingredients have been studied.

This work aimed to investigate whether a three-component co-amorphous system can be created reliably using a melt-quench method as way to stabilise amorphous materials by the improvement of their singular glass transitions and stability upon storage. The delivery of threecomponent co-amorphous systems would have the advantage of allowing the simultaneous administration of APIs, to reduce the number of medications consumed by the patient and therefore improve patient compliance. Multicomponent co-amorphous systems could be used to combine the administration of two APIs that act in synergy and a chemical ingredient that facilitates their absorbance, as for example the caffeine.

Among the selected active crystalline ingredients majority were characterised by poor solubility in water (Table 1). The generation of multiple component coamorphous system aimed to improve the apparent solubility and dissolution rate of the co-amorphous constituents. In the pharmaceutical field, there is a great interest in the systematic knowledge of the influence of the third component as it is not yet defined.

\section{Materials and methods}

Materials were chosen from initial preliminary test where different APIs were analysed using differential scanning calorimetry (DSC) to determine their propensity to form amorphous or crystalline materials upon cooling from a melt with different cooling rates.

Piroxicam (PXC) (Sigma-Aldrich, Lot: SLBG9097 V) and indomethacin (IND) (Tokyo Chemical Industry, Lot: JU2BN-AB) were selected due to the formation of stable amorphous state with glass-transition temperatures above room temperature.

The third components added to the binary combination of PXC and IND were chosen from the API screening previously described. Benzamide (BZD) (Sigma-Aldrich, Lot: STBF1753 V) and caffeine (CAF) (Sigma-Aldrich, Lot: S21606-124) were selected due to their strong tendency to crystallise on even when melted material was subjected to Newtonian cooling. Acetaminophen (SigmaAldrich, Lot: SLBH0185 V) and clotrimazole (Tokyo Chemical Industry, Lot: PCZNB-QA) were chosen as they showed a propensity towards forming an amorphous on cooling. Physical mixtures were prepared in 1:1:1 molar ratio.

The production of amorphous samples was conducted by melting and rapidly cooling within the differential scanning calorimetry (DSC) instrument as rapid cooling of the melted sample is one of the many validated techniques used to generate an amorphous from a crystalline material [25]. Before analysis, all samples were finely ground using an agate mortar and pestle to ensure a homogenous distribution of components and to reduce the possibility of thermal lag within larger particles.

Physical mixtures and melt-cooled products were characterised with thermogravimetric analysis (TGA), hotstage microscopy (HSM), DSC, X-ray diffraction (XRD) 
Table 1 Solubility in water of selected ingredients based on data collected in PubChem database [24]

\begin{tabular}{lll}
\hline Chemicals & Solubility in water/mg $\mathrm{mL}^{-1}$ & Solubility description based on pharmacopoeia definitions \\
\hline PXC & 0.9370 & Sparingly soluble \\
IND & 23.0000 & Sparingly soluble \\
BZD & 0.0182 & Slightly soluble \\
CAF & $2.16 \times 10^{4}$ & Freely soluble \\
AC & 0.0227 & Slightly soluble \\
CTMZ & 29.8400 & Sparingly soluble \\
\hline
\end{tabular}

and attenuated total reflection-Fourier transform infrared spectroscopy (ATR-FTIR). Physical mixtures were analysed to verify that grinding did not alter the solid state of the sample, while the analysis of the products assured that the adopted preparation method induced complete amorphisation of the mixture components.

TGA was conducted using the Q5000 IR TGA (TA Instruments, UK) in aluminium pans with sample size $2.0 \pm 0.5 \mathrm{mg}$. Samples were heated from ambient temperature $\left(20{ }^{\circ} \mathrm{C}\right)$ to $300{ }^{\circ} \mathrm{C}$ at $10{ }^{\circ} \mathrm{C} \mathrm{min}{ }^{-1}$, under nitrogen $\left(25 \mathrm{~mL} \mathrm{~min}^{-1}\right)$. HSM was conducted using a Mettler Toledo FP90 Central Processor with a FP82HT hot stage. The heating programme used was $10^{\circ} \mathrm{C} \mathrm{min} \operatorname{mom}^{-1}$ from 30 to $300{ }^{\circ} \mathrm{C}$. This allowed the visual identification of thermal events (melting, crystallisation, evaporation and degradation). These data were combined with that gathered from TGA to determine the maximum temperature for the DSC experiments. DSC was carried out using a Q2000 DSC (TA Instruments, UK) in hermetically sealed Tzero aluminium pans with $2.0 \pm 0.5 \mathrm{mg}$ of sample. Heating rates were kept consistent throughout experiments to ensure comparable data; however, the end temperature of experiments was different for each mixture. Three heating and cooling cycles were conducted for the samples to assure the homogeneity of the products and to evaluate possible differences in $T_{\mathrm{g}}$ measured in each heating cycle.

Experiments were conducted in triplicate under nitrogen

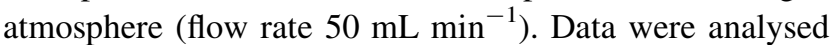
using TA Advantage Universal Analysis V5.5.22 software. Co-amorphous systems were produced in situ using the capability of the DSC to control heating and cooling rates and then used to characterise the thermal transitions of the products.

Samples were equilibrated at $-80{ }^{\circ} \mathrm{C}$ and then heated to $180{ }^{\circ} \mathrm{C}$ with $10{ }^{\circ} \mathrm{C} \mathrm{min}^{-1}$ heating rate to erase the solid history of the samples and ensure mixing of the component molecules to form a homogeneous dispersion. After melting, the samples were cooled. To analyse the propensity of the materials to convert into amorphous, crystalline or a mixture of the phases, two different cooling rates were selected as follows: a fast cooling rate of $20{ }^{\circ} \mathrm{C} \min ^{-1}$ and a slow cooling rate of $5^{\circ} \mathrm{C} \mathrm{min}{ }^{-1}$ were chosen. All physical mixtures were heated to analyse the generated co- amorphous. Experiments were conducted using multiple heating and cooling cycles to determine the reproducibility of the thermal events over repeated cycles. During the final cooling ramp, the samples were brought to $20^{\circ} \mathrm{C}$ and subsequently stored in a temperature-controlled room at $20{ }^{\circ} \mathrm{C}$. Experiments were conducted in triplicate to verify the reproducibility of the obtained results.

XRD was conducted using a D8 Advance X-ray Diffractometer (Bruker, Germany) with theta-theta geometry in reflection mode. $\mathrm{Cu} \mathrm{K} \alpha$ radiation at $40 \mathrm{kV}$ and $40 \mathrm{~mA}$ was used to irradiate samples from a $0.2-\mathrm{mm}$ exit slit. Data collection was between $2^{\circ}$ and $40^{\circ} 2 \theta$, step size of $0.02^{\circ}$ and a counting time of $0.3 \mathrm{~s}$ per step. Data collection was carried out using DIFFRAC plus XRD Commander Version 2.6.1 software (Bruker-AXS), qualitative assessment with the aid of EVA version 16.0 (Bruker-AXS). The Spectrum Two ${ }^{\text {TM }}$ FTIR spectrometer (PerkinElmer, UK) fitted with the diamond/ZnSe ATR (single reflection) accessory was used. Sixteen scans were collected over the range of $4000-650 \mathrm{~cm}^{-1}$. Data were analysed using the Spectrum $10^{\mathrm{TM}}$ software suite.

The initial stability study was conducted under laboratory conditions over period of 1 month to assess whether generated co-amorphous system will remain intact, without exposure to any exaggerated conditions. Samples were stored in sealed glass containers at $20{ }^{\circ} \mathrm{C}$ away from excessive vibration and sunlight. They were tested every 7 days using DSC to analyse changes in transitions and therefore the solid state of the systems.

\section{Results and discussion}

\section{Differential scanning calorimetry}

DSC traces (Fig. 1) showed that indomethacin converts into an amorphous upon rapid cooling $\left(20{ }^{\circ} \mathrm{C} \mathrm{min}^{-1}\right)$ with a $T_{\mathrm{g}}$ of $47.9^{\circ} \mathrm{C}$, which is stable upon heating. The PXC subjected to the same conditions formed an amorphous with a $T_{\mathrm{g}}$ of $64.6^{\circ} \mathrm{C}$ which recrystallises on reheating at the temperature of $138.1^{\circ} \mathrm{C}$ and then melts at $181.4{ }^{\circ} \mathrm{C}$. This also shows the polymorphism exhibited by piroxicam [26]. 


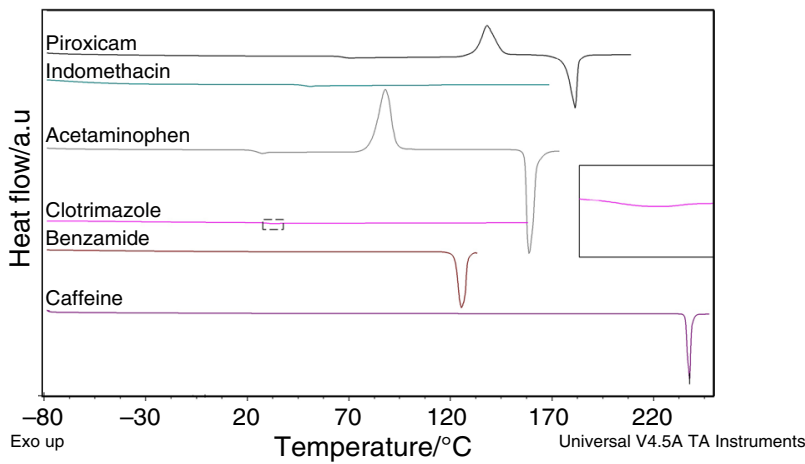

Fig. 1 DSC overlay of the pure chemicals, traces presented are relative to the second heating cycle after a fast cooling of the melted material

Thermal transitions of other starting materials are shown in Table 2.

The physical mixture composed of PXC and IND at a 1:1 molar ratio was analysed in the DSC, the sample was heated above the melting point of both constituents, cooled at $20{ }^{\circ} \mathrm{C} \mathrm{min}^{-1}$ and reheated to characterise the generated product.

The DSC trace of the heating cycle after subsequent cooling revealed a single $T_{\mathrm{g}}$ at $57.6{ }^{\circ} \mathrm{C}$ which was stable upon cooling, as no recrystallisation occurred, and no recrystallisation was present on heating. This was an indication of the generation of a co-amorphous system comprising PXC and IND characterised by a $T_{\mathrm{g}}$ intermediate between the $T_{\mathrm{g}} \mathrm{s}$ of the single components. Hence, the amorphous IND was stabilised by the interaction with the amorphous PXC as obtained $T_{\mathrm{g}}$ is greater than $T_{\mathrm{g}}$ of IND. The IND is in turn stabilising the amorphous PXC and preventing it from crystallising on reheating.

Third components were added to the binary mixture of IND and PXC, these were characterised in DSC as in Table 1, physical mixtures were in 1:1:1 molar ratios. Coamorphous systems were produced in situ using the capability of the DSC to control heating and cooling rates and then used to characterise the thermal transitions of the products.

The physical mixture of PXC-IND-BZD cooled at $20{ }^{\circ} \mathrm{C} \mathrm{min}{ }^{-1}$ had only a single $T_{\mathrm{g}}$ in the second heating cycle at $31.0^{\circ} \mathrm{C}$; therefore, these characteristics were associated with a co-amorphous system, which was further analysed. The BZD as pure compound showed a strong propensity to form crystalline material upon quench cooling giving such an exothermic response that the signal became a loop instead of a peak as the temperature of the cell was increased. Because of the strong propensity of the BZD to recrystallise, the generated ternary mixture had a $T_{\mathrm{g}}$ lower than the glass transitions of the other components.

DSC traces of the mixture with CAF presented no crystallisation upon cooling, indicating the generation of an amorphous material and a single $T_{\mathrm{g}}$ at $45.8^{\circ} \mathrm{C}$, which recrystallised at $106.6^{\circ} \mathrm{C}$ and then melted at $131.3^{\circ} \mathrm{C}$. These two events can be shown to be of very close enthalpies, which indicate it is a single crystal phase (one polymorph) crystallising from the mixture and then melting again. This also shows that the initially created material was entirely amorphous. The melting point of the recrystallised material was compared with the melting temperatures of the single pure components of the system and of their polymorphic forms. However, this comparison was not sufficient to identify the entity that undergoes recrystallisation.

Both CAF and BZD, although as pure compounds presented the propensity to generate crystalline materials upon heating after cooling of the melted compound, are shown to generate stable co-amorphous ternary systems in association with PXC and IND. The $T_{\mathrm{g}}$ of the co-amorphous system containing CAF was significantly higher than the $T_{\mathrm{g}}$ of the co-amorphous incorporating BZD. This is likely related to the elevated $M_{\mathrm{p}}$ of the $\mathrm{CAF}$, in comparison with $\mathrm{BZD}$, and therefore to the strong interactions existing between the molecules of CAF.

The amorphous form of pure $\mathrm{AC}$ has the lowest glass transition of all the examined compounds; however, the

Table 2 Thermal event measured in DSC traces of pure compounds $(n=3)$

\begin{tabular}{|c|c|c|c|c|c|}
\hline \multirow[t]{2}{*}{ Chemicals } & \multirow[t]{2}{*}{ Melting point on initial heating $/{ }^{\circ} \mathrm{C}$} & \multirow[t]{2}{*}{ Crystallisation on cooling $/{ }^{\circ} \mathrm{C}$} & \multicolumn{3}{|c|}{ Thermal events on 2 nd heating $/{ }^{\circ} \mathrm{C}$} \\
\hline & & & $T_{\mathrm{g}}$ & $T_{\mathrm{c}}$ & $T_{\mathrm{m}}$ \\
\hline PXC & $203.1 \pm 0.1$ & - & $64.6 \pm 1.0$ & $138.1 \pm 0.9$ & $181.4 \pm 0.6$ \\
\hline IND & $161.1 \pm 0.1$ & - & $47.9 \pm 0.7$ & - & - \\
\hline BZD & $126.2 \pm 0.3$ & $98.5 \pm 0.7$ & - & - & $125.5 \pm 0.1$ \\
\hline CAF & $236.7 \pm 0.1$ & $232.1 \pm 0.6$ & - & - & $237.7 \pm 0.1$ \\
\hline $\mathrm{AC}$ & $169.8 \pm 0.2$ & - & $24.9 \pm 0.6$ & $87.9 \pm 0.4$ & $158.6 \pm 0.7$ \\
\hline CTMZ & $145.5 \pm 0.1$ & - & $30.1 \pm 0.3$ & - & - \\
\hline
\end{tabular}

$T_{\mathrm{g}}$, glass transition; $T_{\mathrm{c}}$, crystallisation; $T_{\mathrm{m}}$, melting 
glass transition of this co-amorphous is dramatically higher than the glass transition of the pure AC, showing the potential of this approach to stabilising low $T_{\mathrm{g}}$ materials. The CTMZ was characterised by a low $T_{\mathrm{g}}$ at $30.1{ }^{\circ} \mathrm{C}$, significantly lower than the glass transitions of the pure IND and PXC; however, the co-amorphous generated by the melting of this three-component mixture had a $T_{\mathrm{g}}$ at $53.3{ }^{\circ} \mathrm{C}$, very similar with the glass transition of the binary system. The ternary system has therefore stabilised the amorphous CTMZ without altering the stability of the PXC-IND co-amorphous system.

The formulations described above were also analysed with a cooling rate of $5{ }^{\circ} \mathrm{C} \min ^{-1}$ cooling. From Table 3, it is possible to observe the difference in glass transition measured for ternary co-amorphous from the heating cycle after cooling rate of 20 and $5{ }^{\circ} \mathrm{C} \mathrm{min}-1$ is smaller than the difference in $\mathrm{Tg}$ values encountered for the binary system. It is important to notice that the cooling rate has not influenced the PXC-IND-CAF system, which crystallises upon heating and then melts at the same temperature obtained from DSC traces of the heating following the fast cooling (Fig. 2).

Repeatability was tested by exposing every sample to consecutive heating and cooling cycles. In these experiments, heating and cooling rates were not modified but were cycled multiple times. The standard deviation between the glass-transition temperatures of the PXC-IND was $0.4{ }^{\circ} \mathrm{C}$ when evaluated in heating cycles after fast cooling and $0.2{ }^{\circ} \mathrm{C}$ in slow cooling experiments, whereas ternary mixtures revealed higher variations in $T_{\mathrm{g}}$ measured in fast and slow cooling experiments (Table 3 ). This points out to the importance of careful selection of appropriate cooling rate in order to obtain reproducible quality of coamorphous system.

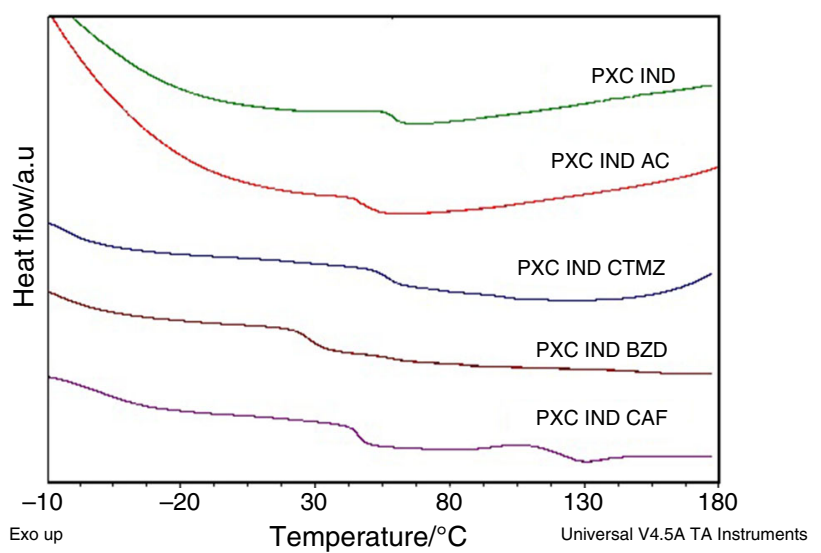

Fig. 2 DSC overlay of binary and ternary mixtures, traces presented are relative to the second heating cycle after a fast cooling of the melted material

\section{Hot-stage microscopy}

Each physical mixture was subjected to repeated heating and cooling cycles with the same ramp rate and temperature limits as used in the DSC analysis. HSM video revealed the same thermal transitions identified in the DSC traces confirming those results. Additional information was gathered from the HSM video of the PXC-IND-BZD system (Fig. 3). The video collected from the heating of the co-amorphous system confirmed a glass transition, which started at $47.3{ }^{\circ} \mathrm{C}$ (Fig. 3b) and finished at $92.4{ }^{\circ} \mathrm{C}$ (Fig. 3c). However, unlike the DSC data, HSM showed evidence of the generation of crystalline material at $100.0^{\circ} \mathrm{C}$, with defined needle-like shape, emerging from the rubbery material (Fig. 3d). These crystals were not homogenously distributed in the melted sample and grew reaching maximum dimensions at $148.3{ }^{\circ} \mathrm{C}$ (Fig. 3e), and melting temperature was observed in a range from 152.6 to $160.8^{\circ} \mathrm{C}$ (Fig. 3f, g).

The melting temperature of the newly generated crystals was compared with the melting temperature of the pure

Table 3 Thermal events measured from heating after cooling from a melt with cooling rates of 20 and $5{ }^{\circ} \mathrm{C} \min ^{-1}(n=3)$

\begin{tabular}{|c|c|c|c|c|c|c|c|}
\hline \multirow[t]{2}{*}{ Sample } & \multicolumn{3}{|c|}{$\begin{array}{l}\text { Thermal events on heating after } \\
20{ }^{\circ} \mathrm{C} \min ^{-1} \text { cooling } /{ }^{\circ} \mathrm{C}\end{array}$} & \multicolumn{3}{|c|}{$\begin{array}{l}\text { Thermal events on heating after } \\
5^{\circ} \mathrm{C} \text { min }^{-1} \text { cooling } /{ }^{\circ} \mathrm{C}\end{array}$} & \multirow[t]{2}{*}{$\Delta T_{\mathrm{g}}$ between adopted cooling rates $/{ }^{\circ} \mathrm{C}$} \\
\hline & $T_{\mathrm{g}}$ & $T_{\mathrm{c}}$ & $T_{\mathrm{m}}$ & $T_{\mathrm{g}}$ & $T_{\mathrm{c}}$ & $T_{\mathrm{m}}$ & \\
\hline PXC-IND & $57.6 \pm 0.4$ & - & - & $52.5 \pm 0.2$ & - & - & 5.1 \\
\hline PXC-IND-BZD & $31.0 \pm 1.2$ & - & - & $28.8 \pm 1.3$ & - & - & 2.2 \\
\hline PXC-IND-CAF & $45.8 \pm 0.5$ & $106.6 \pm 0.4$ & $131.3 \pm 0.4$ & $44.5 \pm 1.5$ & $106.6 \pm 0.4$ & $131.3 \pm 0.4$ & 1.3 \\
\hline PXC-IND-AC & $47.1 \pm 1.3$ & - & - & $46.1 \pm 2.1$ & - & - & 1.0 \\
\hline $\begin{array}{l}\text { PXC-IND- } \\
\text { CTMZ }\end{array}$ & $53.3 \pm 1.2$ & - & - & $53.5 \pm 3.3$ & - & - & -0.2 \\
\hline
\end{tabular}

$T_{\mathrm{g}}$, glass transition; $T_{\mathrm{c}}$, crystallisation; $T_{\mathrm{m}}$, melting 


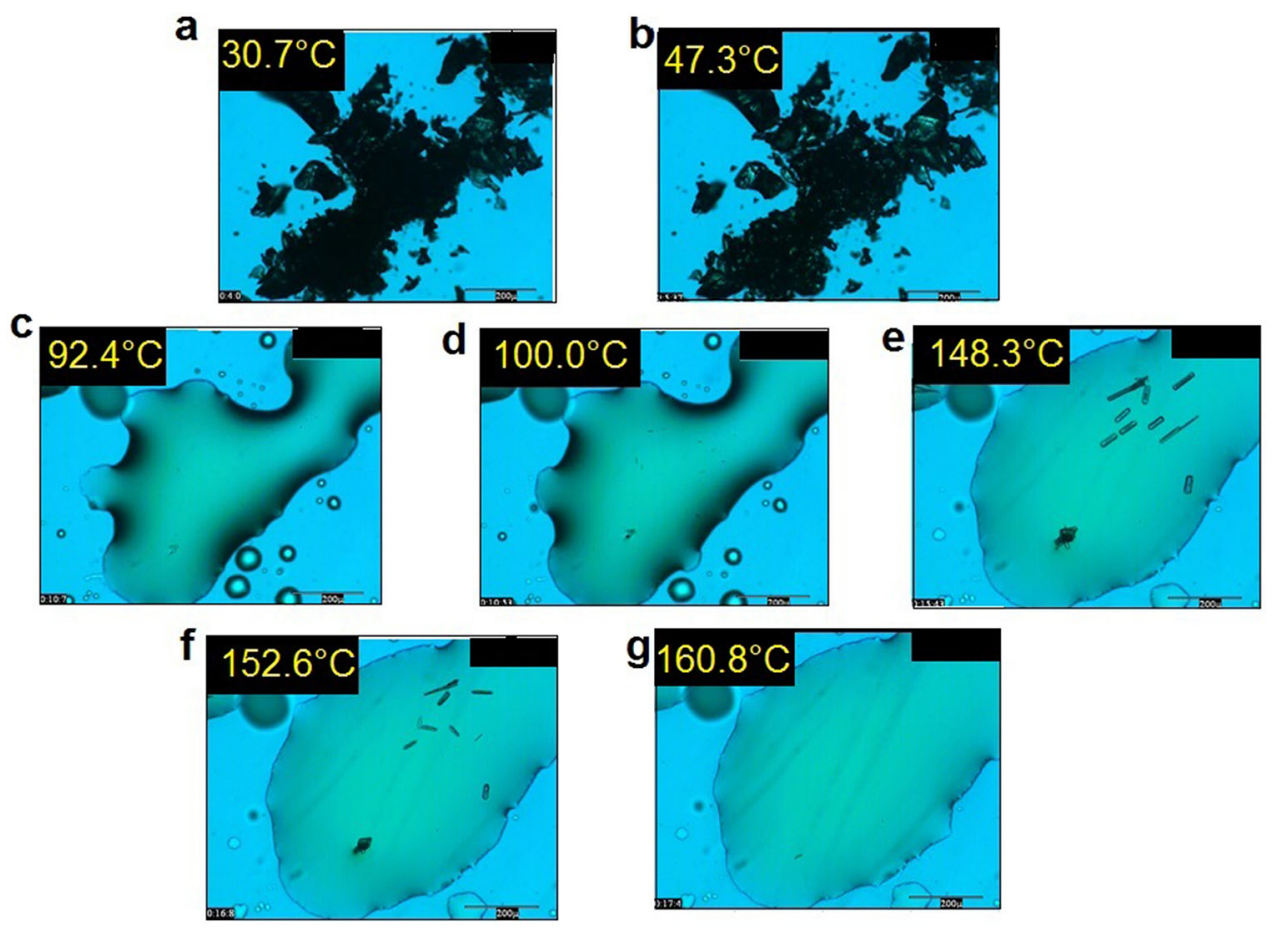

Fig. 3 Images extracted from the heating process of PXC-IND-BZD realised under HSM. Each section describes as follows: a the structure of the examined particle at the starting temperature; $\mathbf{b}$ the initial stages of the glass transition $\left(47.3^{\circ} \mathrm{C}\right)$; $\mathbf{c}$ generated rubbery amorphous $\left(92.4{ }^{\circ} \mathrm{C}\right)$; d appearance of the first crystals from the rubbery amorphous $\left(100^{\circ} \mathrm{C}\right)$; e crystal growth $\left(148.3{ }^{\circ} \mathrm{C}\right)$; f melting of crystals generated $\left(152.6^{\circ} \mathrm{C}\right)$; $\mathbf{g}$ final stage of melting $\left(160.8^{\circ} \mathrm{C}\right)$ components of the system and possible polymorphic forms, but it was not possible to identify the component that recrystallised. PXC-IND-BZD was the only generated coamorphous that presented this peculiar recrystallisation behaviour where the DSC did not show the thermal event. This suggests the possibility of concurrently processes producing a net zero heat flow or that the energy released during recrystallisation is low causing the DSC to show no signal for the event. However, the recrystallisation observed in the HSM might be initiated by the energy introduced in the sample when scrapped from the DSC pan.

To further characterise the PXC-IND-BZD co-amorphous, a fresh sample was heated up the temperature where the initial traces of the crystals were visible $\left(100{ }^{\circ} \mathrm{C}\right)$ and left isothermal for $1 \mathrm{~h}$. A similar process was carried out for the PXC-IND-CAF co-amorphous, which has shown recrystallisation of a material upon heating of the created co-amorphous. This sample showed homogeneous recrystallisation upon heating at $83{ }^{\circ} \mathrm{C}$; therefore, the sample was heated at $10{ }^{\circ} \mathrm{C} \mathrm{min}{ }^{-1}$ up to $83{ }^{\circ} \mathrm{C}$ and then left isothermal for $1 \mathrm{~h}$ (Figs. 4, 5).

Both samples showed a clear increase in crystal dimensions over the isothermal period. In the PXC-INDBZD, co-amorphous, crystals were formed initially in the borders of the rubbery material and in localised nucleation centres. Crystal growth was quantified from the video measuring length of the selected crystals with the HSM software at specified time intervals. The growth of the crystals was analysed up to the moment where the crystal encountered others making difficult to quantify the length. Results showed an initial elevated length increase starting at $0.07 \mu \mathrm{m} \mathrm{s}^{-1}$ after only $30 \mathrm{~s}$ and decreasing to $0.03 \mu \mathrm{m} \mathrm{s}^{-1}$ after $90 \mathrm{~s}$ of isothermal. Interestingly, the growth was stable at $0.04 \mu \mathrm{m} \mathrm{s}^{-1}$ from $180 \mathrm{~s}$ onwards until the end of the experiment.

In the PXC-IND-CAF, co-amorphous crystals appear to generate homogeneously throughout the entire structure and to grow progressively, promoting the generation of new crystals from the rubbery sample. Because of the elevated density of the crystals, it was not possible to accurately measure the length of the crystals and therefore the kinetics of crystal growth.

\section{X-ray diffraction}

XRD was used to characterise the solid state of the initial materials, physical mixtures and co-amorphous systems by comparing the diffractograms to PDF-2 database entries (ICDD, 2008). Diffractograms of the physical mixtures presented peaks belonging to each component of the 

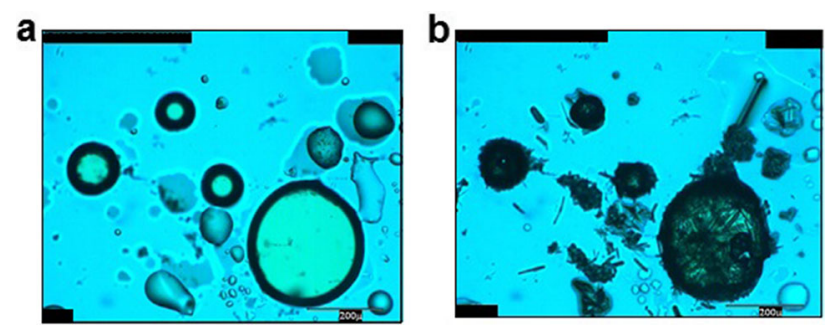

Fig. 4 Images of PXC-IND-BZD co-amorphous subjected to heating above melting point up to $100{ }^{\circ} \mathrm{C}$ when crystallisation starts (a) and left isothermal for $1 \mathrm{~h}$ (b) to allow crystal growth
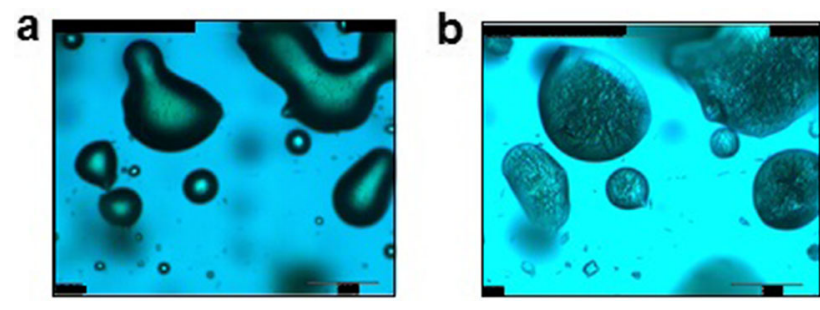

Fig. 5 Images of PXC-IND-CAF co-amorphous subjected to heating above melting point up to $83{ }^{\circ} \mathrm{C}$ when crystallisation starts (a) and left isothermal for $1 \mathrm{~h}(\mathbf{b})$ to allow crystal growth

mixture. This indicates that the grinding adopted to generate the physical mixtures did not alter the solid state of the components. Data were processed with the EVA analysis software for the quantification of the crystallinity of the systems, which revealed no traces of amorphous materials.

Analysis of the co-amorphous system has confirmed that the generated materials were amorphous confirming what observed in the DSC curves, characterised by a single glass transition and no melting points. The analysis with EVA confirmed that for each sample $100 \%$ of the material was in the amorphous state. The co-amorphous system of PXCIND and AC revealed a diffraction peak at $38^{\circ}(2 \theta)$; therefore, the sample was retested up to $60^{\circ}(2 \theta)$ to evaluate the possible presence of crystalline materials of inorganic origin. Analysis revealed that the sample presented diffraction peaks typical of aluminium, material from the vessel used to generate the co-amorphous systems (Figs. 6, 7).

Co-amorphous systems containing BZD and CAF kept isothermal for $1 \mathrm{~h}$ at the starting temperature of the crystallisation were analysed with the same XRD methods used for the samples described above. Results for the PXC-INDBZD allowed for the identification of the recrystallised material as PXC. The diffractogram of the sample of coamorphous PXC-IND-CAF after being held isothermal at the crystallisation temperature showed diffraction peaks that were not identified as belonging to the pure components or any of their known polymorphic forms. This suggests a number of possibilities including a polymorphic form of a single component or a co-crystal comprised of an unknown combination of at least two of the three starting materials. This is shown in Fig. 8 where the crystalline material present in the mixture of PXC-IND-BZD clearly matches that of PXC whereas the diffractogram for PXCIND-CAF does not.

\section{Fourier transform infrared spectroscopy}

Infrared spectroscopy provides information on both the chemical and physical states, and it was used to further characterise the solid state of pure compounds, physical mixtures and products. Molecular bonding vibrational frequencies are affected the molecular environment. When attempting to change the environment, such as changing the material from crystalline to amorphous, these frequencies will shift which can confirm successful modification of the environment.

Physical mixtures were characterised by bands relative to the crystalline components. The spectra of all tested physical mixtures were characterised by sharp bands typical of the crystalline state. Therefore, data indicate that in the physical mixtures, the components were not interacting and that the grinding used to generate the dispersion did not influence the solid state of the adopted materials. The generated co-amorphous systems were characterised by broad bands, with absorbance at the same wavelengths as the physical mixtures. This shows that no chemical interaction has occurred during the heating process and that the differences in peak shape are due to the change from crystalline to amorphous.

Broadening is typical of amorphous materials. Due to the lack of long-range order a specific bond present, the amorphous material has numerous slightly different arrangements with neighbouring molecules, which shifts the vibrational frequency. Therefore, FTIR results were in agreement with DSC and XRD data that indicate that the products of quench cooling were amorphous.

Band broadening has reduced significantly the band at $3338 \mathrm{~cm}^{-1}$ relative to the pyridin-2-yl-amino stretching of the piroxicam [27]. This band was present in all physical mixtures, but not visible in the co-amorphous systems. Two strong and resolute peaks at 1715 and $1690 \mathrm{~cm}^{-1}$ relative to the $\mathrm{C}=\mathrm{O}$ stretching of indomethacin and piroxicam were present in all physical mixtures. However, due to peak broadening of amorphous materials, these were merged in a single peak and shifted at $1680 \mathrm{~cm}^{-1}$.

Another band shift recognised between crystalline and amorphous samples was relative to the $\mathrm{C}-\mathrm{H}$ stretching which was measured at $2970 \mathrm{~cm}^{-1}$ in the crystalline 


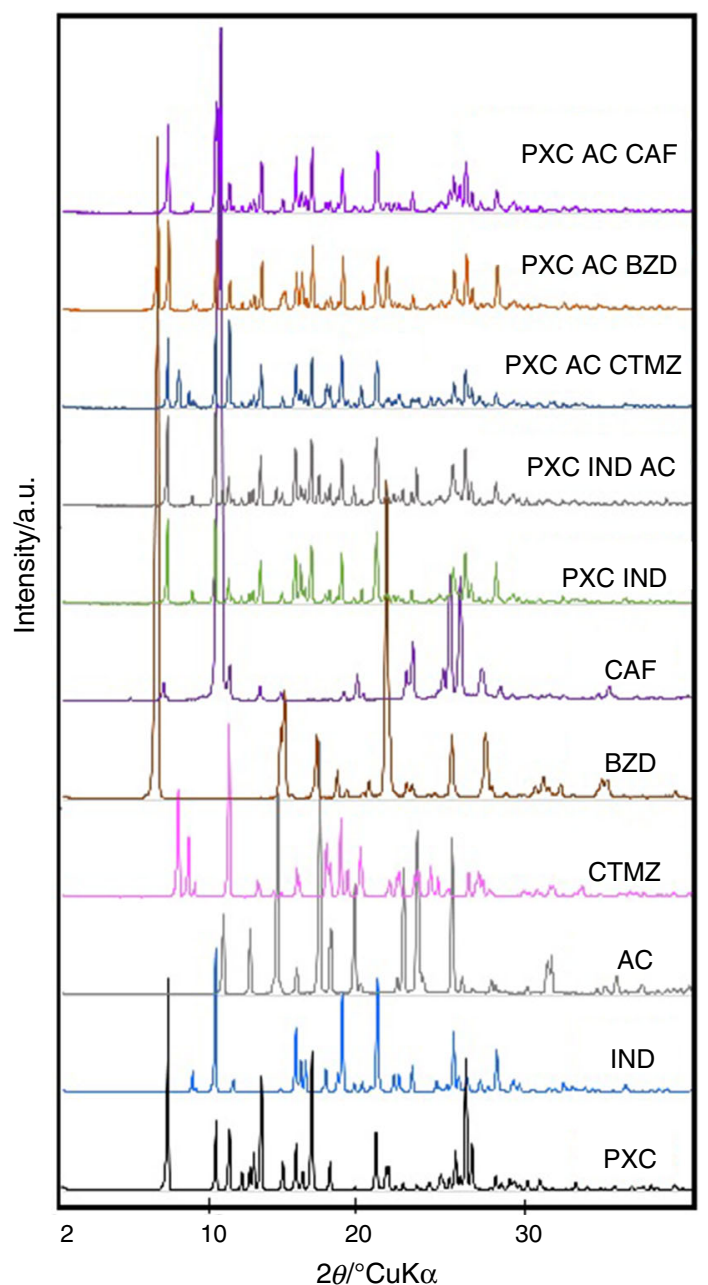

Fig. 6 Overlay of diffractograms of pure chemicals and physical mixtures used to generate co-amorphous systems

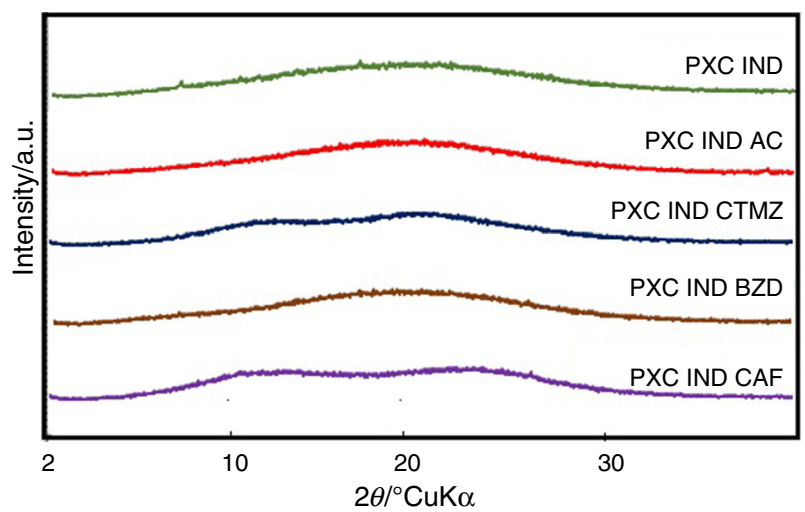

Fig. 7 Overlay of diffraction traces of generated co-amorphous systems

samples and in the co-amorphous samples at $2980 \mathrm{~cm}^{-1}$. Band shifting indicates that components of the studied coamorphous systems were not only solid dispersions in amorphous phase, but also interacting. In PXC-IND, PXC-

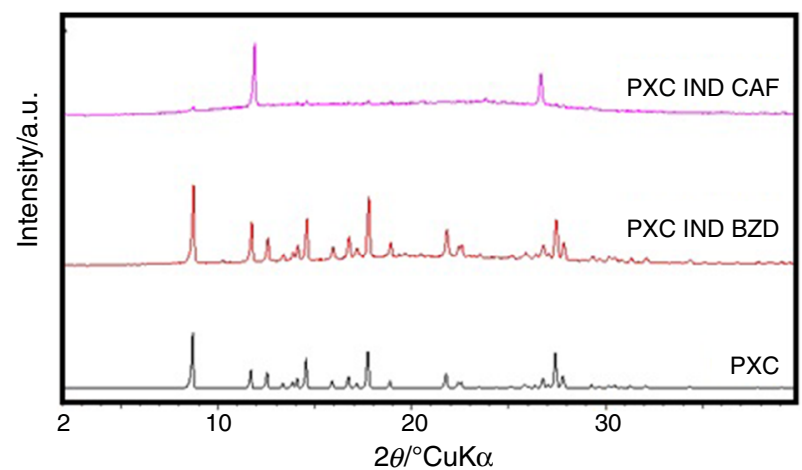

Fig. 8 Overlay of diffraction traces of pure piroxicam (bottom), PXCIND-BZD co-amorphous left isothermal for an hour at $100{ }^{\circ} \mathrm{C}$ (middle) and XC-IND-CAF co-amorphous left isothermal for an hour at $183^{\circ} \mathrm{C}$ (top)

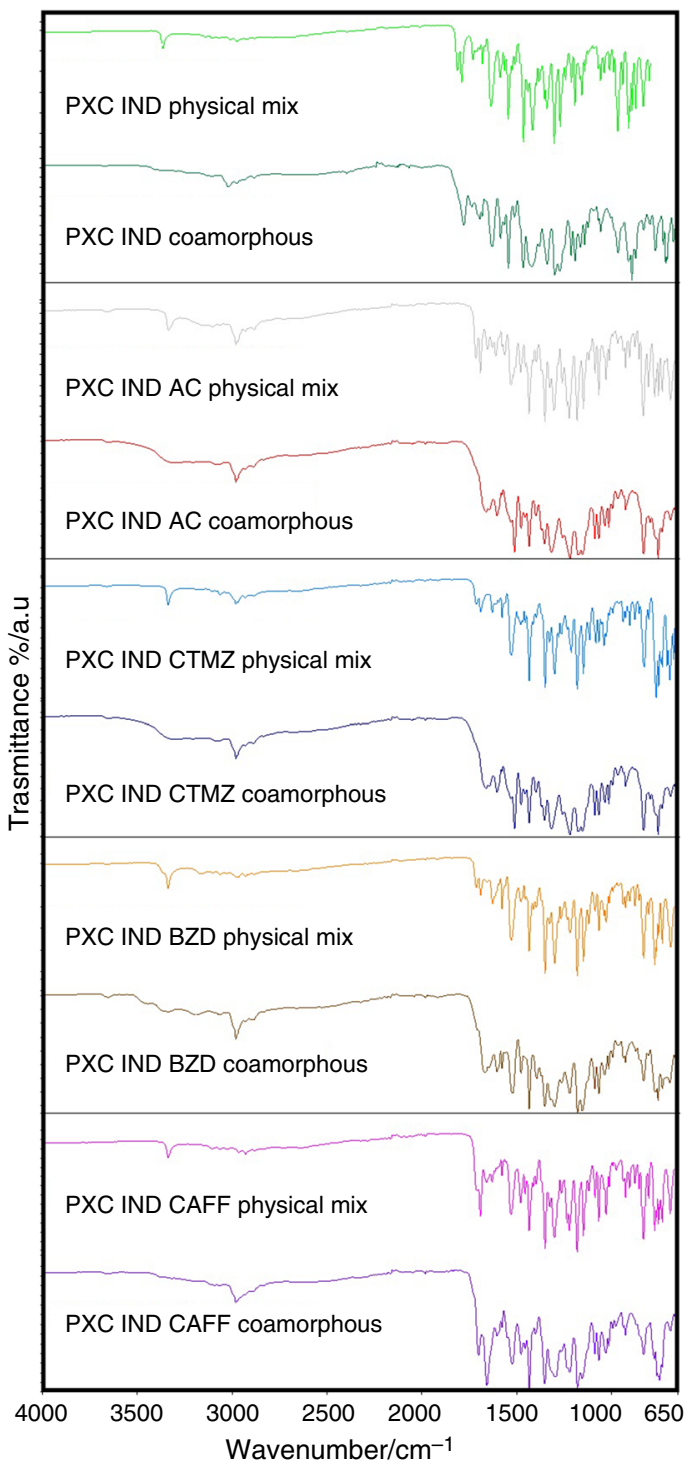

Fig. 9 FTIR overlay of pure chemicals, physical mixtures and generated co-amorphous systems 
Table 4 Glass-transition temperature of co-amorphous samples collected over 4-week period storage $(n=3)$

\begin{tabular}{|c|c|c|c|c|c|c|}
\hline Systems & $\begin{array}{l}T_{\mathrm{g}} \text { fresh } \\
\text { sample } /{ }^{\circ} \mathrm{C}\end{array}$ & $\begin{array}{l}T_{\mathrm{g}} \text { sample stored for } \\
1 \text { week } /{ }^{\circ} \mathrm{C}\end{array}$ & $\begin{array}{l}T_{\mathrm{g}} \text { sample stored for } \\
2 \text { weeks } /{ }^{\circ} \mathrm{C}\end{array}$ & $\begin{array}{l}T_{\mathrm{g}} \text { sample stored for } \\
3 \text { weeks } /{ }^{\circ} \mathrm{C}\end{array}$ & $\begin{array}{l}T_{\mathrm{g}} \text { sample stored for } \\
4 \text { weeks } /{ }^{\circ} \mathrm{C}\end{array}$ & $\begin{array}{l}\Delta T_{\mathrm{g}} \text { after } \\
4 \text { weeks } /{ }^{\circ} \mathrm{C}\end{array}$ \\
\hline PXC-IND & $57.6 \pm 0.4$ & $53.0 \pm 2.6$ & $52.0 \pm 2.2$ & $49.4 \pm 1.9$ & $44.4 \pm 0.6$ & 13.2 \\
\hline $\begin{array}{l}\text { PXC-IND- } \\
\text { BZD }\end{array}$ & $31.0 \pm 1.2$ & $26.6 \pm 0.3$ & $26.1 \pm 0.6$ & $25.6 \pm 0.7$ & $27.3 \pm 0.6$ & 3.7 \\
\hline $\begin{array}{l}\text { PXC-IND- } \\
\text { CAF }\end{array}$ & $45.8 \pm 0.5$ & $42.8 \pm 0.9$ & $42.0 \pm 0.7$ & $42.1 \pm 0.4$ & $42.4 \pm 0.2$ & 2.1 \\
\hline $\begin{array}{l}\text { PXC-IND- } \\
\text { AC }\end{array}$ & $47.1 \pm 1.3$ & $42.5 \pm 1.2$ & $42.2 \pm 1.4$ & $43.5 \pm 0.9$ & $42.1 \pm 1.6$ & 5.0 \\
\hline $\begin{array}{l}\text { PXC-IND- } \\
\text { CTMZ }\end{array}$ & $53.3 \pm 1.2$ & $48.7 \pm 0.9$ & $52.8 \pm 2.1$ & $46.3 \pm 2.8$ & $44.7 \pm 2.1$ & 8.6 \\
\hline
\end{tabular}

IND-CAFF and PXC-IND-BZD systems, the intensity of this band was higher in the co-amorphous systems than in their crystalline counterparts (Fig. 9).

\section{Stability}

Over the 4 weeks' storage, the binary co-amorphous system of PCX-IND has shown a decrease in $T_{\mathrm{g}}\left(\Delta T_{\mathrm{g}}\right)$ of $13.2{ }^{\circ} \mathrm{C}$, which is significantly higher than the $\Delta T_{\mathrm{g}}$ of all the ternary co-amorphous under analysis. The decrease in $T_{\mathrm{g}}$ that occurred between the $3 \mathrm{rd}$ and the 4 th week was significant for the binary system, whereas the ternary coamorphous appears to have a smaler $\Delta T_{\mathrm{g}}$.

The PXC-IND-CTMZ was characterised by final $\Delta T_{\mathrm{g}}$ of $8.6{ }^{\circ} \mathrm{C}$ which was second only to that of the binary coamorphous (Table 4). The systems that when freshly generated had the highest $T_{\mathrm{g}}$, with respect to the other coamorphous, were characterised by the highest depression in $T_{\mathrm{g}}$ of all the stored samples. The other co-amorphous system where all components, as pure compounds, had the tendency to form amorphous, PXC-IND-AC, showed a $\Delta T_{\mathrm{g}}$ of $5.0^{\circ} \mathrm{C}$. Results have shown that the addition of a third component with tendency to form crystalline material (BZD, CAF) stabilises the system, causing a reduction of the $\Delta T_{\mathrm{g}}$ as shown in Table 4 .

\section{Conclusions}

Three-component co-amorphous systems were reliably generated via a melt-quench method. Components that have tendency to crystallise on cooling, i.e., are not easily converted into amorphous phase, demonstrated not only the ability to form a co-amorphous system when combined into a co-amorphous mixture, but also showed greater stability of created co-amorphous system, with respect to the $T_{\mathrm{g}}$ values compared to compounds with tendency to create an amorphous material on rapid cooling. Short-term stability, over 4 weeks, demonstrated that the ternary system is more stable when compared to the binary system. Unexpectedly it was found that the pure materials, which have a propensity to form crystalline materials on cooling, created more stable three-component systems with a much lower deviation in glass-transition temperature across 4 weeks of storage. Based on this study, it is evident that the $T_{\mathrm{g}}$ of coamorphous system can be altered using appropriate components of ternary mixture. The most commonly used physical parameters, i.e. $T_{\mathrm{m}}$ and $T_{\mathrm{g}}$, may not be sufficient to predict the resulting $T_{\mathrm{g}}$ of the multicomponent co-amorphous systems. Therefore, knowledge of chemical interactions must be taken into account when manipulating $T_{\mathrm{g}}$ and selecting components for a ternary co-amorphous system.

Rapid cooling after melting is confirmed to be a valuable method for the amorphisation of single chemicals and in the generation of complex co-amorphous systems. Improvement in stability of the ternary co-amorphous systems with respect to binary co-amorphous is valuable for the development of complex co-amorphous, especially in the pharmaceutical field where co-amorphous are used to improve apparent solubility and dissolution rate of active ingredients.

Open Access This article is distributed under the terms of the Creative Commons Attribution 4.0 International License (http://creative commons.org/licenses/by/4.0/), which permits unrestricted use, distribution, and reproduction in any medium, provided you give appropriate credit to the original author(s) and the source, provide a link to the Creative Commons license, and indicate if changes were made.

\section{References}

1. Chavan RB, Thipparaboina R, Kumar D, Shastri NR. Co amorphous systems: a product development perspective. Int J Pharm. 2016;515(1):403-15.

2. Edueng K, Mahlin D, Bergström CAS. The need for restructuring the disordered science of amorphous drug formulations. Pharm Res. 2017;34(9):1754-72. 
3. Savjani KT, Gajjar AK, Savjani JK. Drug solubility: importance and enhancement techniques. ISRN Pharm. 2012. https://doi.org/ $10.5402 / 2012 / 195727$.

4. Sun Y, Zhu L, Wu T, Cai T, Gunn EM, Yu L. Stability of amorphous pharmaceutical solids: crystal growth mechanisms and effect of polymer additives. AAPS J. 2012;14(3):380-8.

5. Hancock BC, Parks M. What is the true solubility advantage for amorphous pharmaceuticals? Pharm Res. 2000;17(4):397-404.

6. Graeser KA, Patterson JE, Zeitler JA, Rades T. The role of configurational entropy in amorphous systems. Pharmaceutics. 2010;2(2):224-44.

7. Wang LY, Zhu L, Sha ZL, Li XC, Wang YF, Yang LB, et al. Characterization, thermal stability, and solid-state phase transition behaviors of gestodene polymorphs and amorphous phase. JTAC. 2017;127(2):1533-42.

8. Yu L. Amorphous pharmaceutical solids: preparation, characterization and stabilization. Adv Drug Deliv Rev. 2001;48(1):27-42.

9. Qian F, Huang J, Hussain MA. Drug-polymer solubility and miscibility: stability consideration and practical challenges in amorphous solid dispersion development. J Pharm Sci. 2010;99(7):2941-7.

10. Karolewicz B, Gajda M, Pluta J, Górniak A. The effect of Pluronic F127 on the physicochemical properties and dissolution profile of lovastatin solid dispersions. JTAC. 2016;123(3):2283-90.

11. Yonemochi E, Sano S, Yoshihashi Y, Terada K. Diffusivity of amorphous drug in solid dispersion. JTAC. 2013;113(3):1505-10.

12. De Souza CMP, dos Santos JAB, do Nascimento AL, Chaves Júnior JV, de Lima Ramos Júnior FJ, de Lima Neto SA, et al. Thermal analysis study of solid dispersions hydrochlorothiazide. JTAC. 2018;131(1):681-9.

13. Rumondor ACF, Ivanisevic I, Bates S, Alonzo DE, Taylor LS. Evaluation of drug-polymer miscibility in amorphous solid dispersion systems. Pharm Res. 2009;26(11):2523-34.

14. Dametto PR, Dametto AC, Polese L, Ribeiro CA, Chorilli M, de Freitas O. Development and physicochemical characterization of solid dispersions containing praziquantel for the treatment of schistosomiasis. JTAC. 2017;127(2):1693-706.

15. Rumondor ACF, Stanford LA, Taylor LS. Effects of polymer type and storage relative humidity on the kinetics of felodipine crystallization from amorphous solid dispersions. Pharm Res. 2009;26(12):2599.
16. Górska A, Szulc K, Ostrowska-Ligęza E, Bryś J, WirkowskaWojdyła M. Effect of composition and drying method on glass transition temperature, water sorption characteristics and surface morphology of newly designed $\beta$-lactoglobulin/retinyl palmitate/ disaccharides systems. JTAC. 2017;130(1):177-85.

17. Yoshihashi Y, Iijima H, Yonemochi E, Terada K. Estimation of physical stability of amorphous solid dispersion using differential scanning calorimetry. JTAC. 2006;85(3):689-92.

18. Guo Y, Shalaev E, Smith S. Physical stability of pharmaceutical formulations: solid-state characterization of amorphous dispersions. Trends Anal Chem. 2013;49:137-44.

19. Dengale SJ, Grohganz H, Rades T, Löbmann K. Recent advances in co-amorphous drug formulations. Adv Drug Deliv Rev. 2016;100:116-25.

20. Löbmann K, Grohganz H, Laitinen R, Strachan C, Rades T. Amino acids as co-amorphous stabilizers for poorly water soluble drugs-part 1: preparation, stability and dissolution enhancement. Eur J Pharm Biopharm. 2013;85(3, Part B):873-81.

21. Kaminska E, Adrjanowicz K, Zakowiecki D, Milanowski B, Tarnacka M, Hawelek L, et al. Enhancement of the physical stability of amorphous indomethacin by mixing it with octaacetylmaltose. Inter and intra molecular studies. Pharm Res. 2014;31(10):2887-903.

22. Laitinen R, Löbmann K, Strachan CJ, Grohganz H, Rades T. Emerging trends in the stabilization of amorphous drugs. Int $\mathrm{J}$ Pharm. 2013;453(1):65-79.

23. Yamamura S, Gotoh H, Sakamoto Y, Momose Y. Physicochemical properties of amorphous precipitates of cimetidine-indomethacin binary system. Eur $\mathrm{J}$ Pharm Biopharm. 2000;49(3):259-65.

24. PubChem [Available from: https://pubchem.ncbi.nlm.nih.gov/. Accessed 20/11/2017.

25. Maheswaram MP, Mantheni D, Perera I, Venumuddala H, Riga A, Alexander K. Characterization of crystalline and amorphous content in pharmaceutical solids by dielectric thermal analysis. JTAC. 2013;111(3):1987-97.

26. Vrecer F, Vrbinc M, Meden A. Characterization of piroxicam crystal modifications. Int J Pharm. 2003;256(1-2):3-15.

27. Trivedi MK, Patil S, Shettigar H, Bairwa K, Jana S. Effect of biofield treatment on spectral properties of paracetamol and piroxicam. Chem Sci J. 2015;6(2):98. 